\title{
Cortical growth patterns in relation to autism spectrum disorder in ages 1-2 years
}

\author{
Ryan Plunkett ${ }^{1}$, Emily lannopollo ${ }^{1}$, Chris Basinski ${ }^{2}$, Kara Garcia ${ }^{1,3}$ \\ ${ }^{1}$ Indiana University School of Medicine-Evansville, ${ }^{2}$ Purdue University, Weldon School of Biomedical \\ Engineering, ${ }^{3}$ Indiana University School of Medicine, Department of Radiology and Imaging Sciences
}

Background and Hypothesis: Autism Spectrum Disorder (ASD) is a common neurodevelopmental disorder with a prevalence of $2.76 \%$ among children ages 3-17 in the United States ${ }^{1}$. Some studies have linked total brain volume overgrowth or gyrification changes to $\mathrm{ASD}^{2,3,4}$. However, few have attempted to relate specific growth patterns to ASD. We hypothesize that regional differences in brain growth in subjects aged 12-24 months will correlate with diagnoses from the Autism Diagnostic Observation Schedule (ADOS).

Project Methods: The subjects for this study came from the Infant Brain Imaging Study (IBIS) ${ }^{5}$. The CIVET pipeline was used to segment T1-weighted magnetic resonance images (MRIs) into surfaces using a non-linear classification method ${ }^{5,6,7}$. CIVET quality control outputs were used for validation and to select parameters for the tasks along with previous recommendations ${ }^{5,8}$. Analysis of Functional Neurolmages (AFNI) was used to convert the CIVET output format, and Connectome Workbench was used to calculate surface curvature. Using cortical reconstructions and surface curvatures from 12- and 24-month brains, anatomically-constrained Multimodal Surface Matching (aMSM) was applied to achieve point correspondence and generate individual cortical growth maps ${ }^{9,10}$.

Results: Within the IBIS database, we found 38 individuals with ASD and 121 controls with T1weighted scans at both 12 and 24-month time points. Once individual growth maps have been generated for all subjects, Permutation Analysis of Linear Models (PALM) ${ }^{11}$ will be used to determine statistically significant differences in the cortical growth patterns of ASD versus control groups.

Conclusion and Potential Impact: Research on autism may benefit from longitudinal studies of growth, as opposed to analysis of structural differences at later ages ${ }^{4}$. We concentrate on cortical growth before 24 months, which may serve as an earlier marker of ASD, when abnormal brain growth can be seen yet social deficits are not fully established ${ }^{5}$.

[1] Zablotsky B, Black LI, Blumberg SJ. Estimated Prevalence of Children With Diagnosed Developmental Disabilities in the United States, 2014-2016. NCHS Data Brief 2017. https://www.cdc.gov/nchs/data/databriefs/db291.pdf (accessed April 29, 2019).

[2] Libero LE, Schaer M, Li DD, Amaral DG, Nordahl CW. A Longitudinal Study of Local Gyrification Index in Young Boys With Autism Spectrum Disorder. Cereb Cortex. 2019;29(6):2575-87.

[3] Raznahan A, Toro R, Daly E, Robertson D, Murphy C, Deeley Q, et al. Cortical anatomy in autism spectrum disorder: an in vivo MRI study on the effect of age. Cereb Cortex. 2010;20(6):1332-40.

[4] Duret P, Samson F, Pinsard B, Barbeau EB, Bore A, Soulieres I, et al. Gyrification changes are related to cognitive strengths in autism. Neuroimage Clin. 2018;20:415-23.

[5] Hazlett HC, Gu H, Munsell BC, Kim SH, Styner M, Wolff JJ, et al. Early brain development in infants at high risk for autism spectrum disorder. Nature. 2017;542(7641):348-51.

[6] Shaw P, Malek M, Watson B, Sharp W, Evans A, Greenstein D. Development of cortical surface area and gyrification in attentiondeficit/hyperactivity disorder. Biol Psychiatry. 2012;72(3):191-7.

[7] Ad-Dab'bagh, Y., Einarson, D., Lyttelton, O., Muehlboeck, J.-S., Mok, K., Ivanov, O., Vincent, R.D., Lepage, C., Lerch, J., Fombonne, E., and Evans, A.C. (2006). The CIVET Image-Processing Environment: A Fully Automated Comprehensive Pipeline for Anatomical Neuroimaging Research. In Proceedings of the 12th Annual Meeting of the Organization for Human Brain Mapping, M. Corbetta, ed. (Florence, Italy, Neurolmage). http://www.bic.mni.mcgill.ca/users/yaddab/Yasser-HBM2006-Poster.pdf

[8] Shaw P, Kabani NJ, Lerch JP, Eckstrand K, Lenroot R, Gogtay N, et al. Neurodevelopmental trajectories of the human cerebral cortex. J Neurosci. 2008;28(14):3586-94.

[9] Garcia KE, Robinson EC, Alexopoulos D, Dierker DL, Glasser MF, Coalson TS, et al. Dynamic patterns of cortical expansion during folding of the preterm human brain. Proc Natl Acad Sci U S A. 2018;115(12):3156-61.

[10] Robinson EC, Garcia K, Glasser MF, Chen Z, Coalson TS, Makropoulos A, et al. Multimodal surface matching with higher-order smoothness constraints. Neuroimage. 2018;167:453-65.

[11] Winkler AM, Ridgway GR, Webster MA, Smith SM, Nichols TE. Permutation inference for the general linear model. Neurolmage, 2014;92:381-397 (Open Access) 